\title{
ERRATUM
}

\section{Erratum to: DNMT3B polymorphisms and cancer risk: a meta analysis of 24 case-control studies}

\author{
Shimiao Zhu $\cdot$ Hui Zhang $\cdot$ Yang Tang $\cdot$ \\ Peicai Liu $\cdot$ Jianmin Wang
}

Published online: 16 March 2012

(C) Springer Science+Business Media B.V. 2012

Erratum to: Mol Biol Rep (2012) 39:4429-4437

DOI 10.1007/s11033-011-1231-2

Author affiliations were incorrect in the published article.

They appear correct in this erratum.

The online version of the original article can be found under doi: 10.1007/s11033-011-1231-2.

\section{S. Zhu}

Department of Urology, Cangzhou Central Hospital,

Cangzhou 061001, Hebei Province, China

S. Zhu $\cdot$ Y. Tang $\cdot$ J. Wang $(\bowtie)$

Tianjin Institute of Urology, Pingjiang Road 23, Hexi District,

Tianjin 300211, China

e-mail: shimiaozhu@yahoo.com

H. Zhang

Department of Nephrology, Cangzhou Central Hospital,

Cangzhou 061001, Hebei Province, China

P. Liu

Department of Stomatology, The 2nd Hospital of Tianjin

Medical University, Pingjiang Road 23, Hexi District,

Tianjin 300211, China 